\author{
大 屋 勝 敬*1, 荒 木 嘉 昭*2

\section{Robust Control to Improve Handling Performance of Tractor Semitrailer Combination}

\author{
Masahiro OYA*3 and Yoshiaki ARAKI \\ ${ }^{* 3}$ Department of Mechanical and Control Engineering, Kyushu Institute of Technology, \\ 1-1 Sensui, Tobata, Kitakyushu-shi, Fukuoka, 804-8550 Japan
}

\begin{abstract}
In this paper a new steering control scheme for tractors and semitrailers combination is developed so that good robust steering stability can be assured. To meet this end, at first, a new method to design an ideal model is proposed. Then, a new robust tracking controller with an integrator is developed. In the closed loop system using the proposed controller it is theoretically shown that robust stability can be easily achieved and robust tracking performance can be easily improved by using only one design parameter. It is also shown by numerical simulations that the proposed controller is effective for tractors and semitrailers combination even if nonlinear formulas of tire slip angles are took into consideration.
\end{abstract}

Key Words : Automobile, Semitrailer, Maneuverability, Steering, Motion Control, Robust Control

\section{1.はじめに}

連結車両が何らかの原因で走行不安定になったとき, 操縦者による安定化は小型車両に較べ非常に難しく, 事故が発生すれば，その被害は甚大となる。 この問題 に取り組むため, 連結車両の安定解析 ${ }^{(1)-(3)}$, 操䋛安 定性改善法や自動操舵法 ${ }^{(4)-(9)}$ が提案された. 文献 (4) 〜(9)では, トレーラ重量やタイヤのコーナリング剛 性等の全ての車両パラメータが既知な場合の手法が提 案されている. しかし, 重量変動やコーナリング剛性 変動等の未知パラメータ変動が存在する場合, 上記の 手法を適用しても所期の目的は達成されず，閉ループ 系が不安定となり事故を引き起こす危険性もある.

近年, 上記の問題に対処するため, 多くのロバスト 制御手法が提案された ${ }^{(10)-(16)}$. 文献 $(10) \sim(13)$ では, 理想車線と㢲引車との相対位置・ヨー角を計測し, 牽 引車前輪操舵のみを用いてこれらの状態量を零に近づ け，かつ，牽引車とトレーラとの相対ヨ一角に振動が 起きにくい車線追従法が開発されている. しかし, 車 線と牽引車との相対位置・ヨー角が計測不可能な車線 に対しては適用できないという問題がある. 文献 (14)

$*$ 原稿受付 2005 年 5 月 25 日.

*1 正員, 九州工業大学工学部( 804-8550 北九州市戸畑区仙 水町 1-1)

*2 正員, 東亜大学工学部( 751-8503 下関市一の宮学園町 2 $1)$.

E-mail : oya@entl.kyutech.ac.jp
〜(16)では, 牟引車の横方向速度（あるいは, すべり 角)，ヨーレイト, ならびに, 牽引車とトレーラとの 相対ヨ一角を制御することにより操縦安定性の向上 を行っている. 文献 (14), (15) では牽引車前輪操舵と ヨーモーメントの二つの操作量を用いているが, 三つ の状態を二つの操作量を用いて制御するより, 三つの 操作量を用いて制御した方が制御性能の向上がより期 待される.また, 文献 (14), (16) の手法は, コーナリ ング剛性のみが未知な場合の手法である. 文献 (15) で はトレーラのみの制御法が考察されており, 牽引車の コーナリング剛性変動が考察されていない.

本稿では, すべてのタイヤのコーナリング剛性なら びにトレーラの重量・慣性, 重心位置に未知変動が存在 する場合に対し，牽引車の前後輪操舵ならびにトレー ラ輪操舵を用いたロバスト操舵安定化法を提案する. まず，操縦者の指令操舵角に対する理想的な牟引車の 横方向速度, ヨーレイト, ならびに, 牽引車とトレー ラとの相対ヨ一角を決定するための理想軌道設計法を 提案する. そして, 高い操縦安定性能を実現するため に, この理想軌道に連結車両の状態を追従させるため の積分型ロバスト追従制御法を提案する.

\section{2. 運動方程式}

本稿で考察する 2 輪連結車両モデルを図 1 に示し， 各パラメータの説明を表 1 に示寸. 図 1 の $\ell_{m}$ は連結 


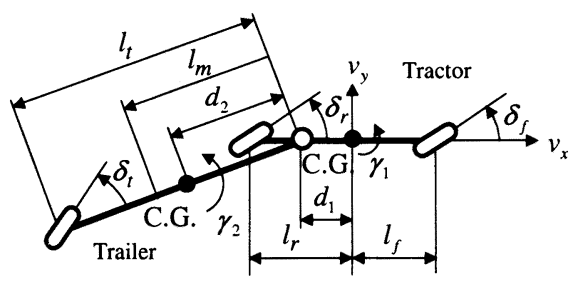

Fig. 1 Tractor semitrailer combination model.

部からの距離を表している. 中高速走行時において牽 引車とトレーラとの相対角 $\varepsilon_{r}(t) \quad\left(\dot{\varepsilon}_{r}(t)=\gamma_{1}(t)-\gamma_{2}(t)\right)$ が微小となることを考慮に入れ, さらに, 牽引車加速 度 $\dot{v}_{x}(t)$ が小さいものと仮定すれば，線形化運動方程 式は次式となる ${ }^{(2),(9)}$. なお, 式 (3) の $M_{p}$ は正定行列 であり, $d_{3}, I_{z 3}$ は $d_{3}=d_{1}+d_{2}, I_{z 3}=I_{z 1}+I_{z 2}$ である.

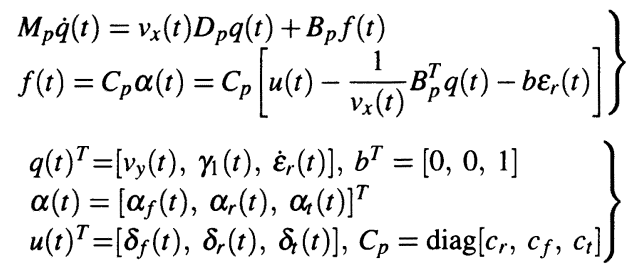

$$
M_{p}=\left[\begin{array}{ccc}
m_{1}+m_{2} & -m_{2} d_{3} & m_{2} d_{2} \\
-m_{2} d_{3} & I_{z 3}+m_{2} d_{3}^{2} & -I_{z 2}-m_{2} d_{2} d_{3} \\
m_{2} d_{2} & -I_{z 2}-m_{2} d_{2} d_{3} & I_{z 2}+m_{2} d_{2}^{2}
\end{array}\right]
$$

$D_{p}=\left[\begin{array}{ccc}0-\left(m_{1}+m_{2}\right) & 0 \\ 0 & m_{2} d_{3} & 0 \\ 0 & -m_{2} d_{2} & 0\end{array}\right], B_{p}=\left[\begin{array}{ccc}1 & 1 & 1 \\ \ell_{f}-\ell_{r} & -\left(d_{1}+\ell_{t}\right) \\ 0 & 0 & \ell_{t}\end{array}\right]$

制御対象に対して以下の仮定を設ける.

$\mathbf{A} 1$ 谹引車の横方向速度 $v_{y}(t)$, ヨーレイト $\gamma_{1}(t)$, 相 対ヨー角 $\varepsilon_{r}(t)$, 相対ヨーレイト $\dot{\varepsilon}_{r}(t)$ を計測している. A2 トレーラの質量 $m_{2}$, 慣性モーメント $I_{z 2}$, 連結 部からトレーラの重心までの距離 $d_{2}$, ならびに, コー ナリング剛性 $c_{f}, c_{r}, c_{t}$ には未知変動が存在する.

\section{3. 理想軌道とそのパラメータ設定法}

3.1 理想軌道 以下において, $\delta_{c}(t)$ は指令舵角, $p$ はラプラス演算子, $\mathscr{L}, \mathscr{L}^{-1}$ はラプラス変換, ラ プラス逆変換を表すものとする.

斢引車の横方向速度ならびにヨーレイトの理想軌道 を次式の形で与える. $\omega_{n}, \zeta, g_{v y}, g_{\gamma}\left(v_{x}\right)$ は正の設計 パラメータである. 牽引車の理想横加速度は $a_{d}(t)=$ $\dot{v}_{y d}(t)+v_{x}(t) \gamma_{d}(t)$ となる.

$$
\left.\begin{array}{l}
v_{y d}(t)=\mathscr{L}^{-1}\left[\frac{g_{v y} \omega_{n}^{2} p}{p^{2}+2 \omega_{n} \zeta p+\omega_{n}^{2}} \mathscr{L}\left[v_{x}(t) \delta_{c}(t)\right]\right] \\
\gamma_{d}(t)=g_{\gamma}\left(v_{x}\right) \mathscr{L}^{-1}\left[\frac{\omega_{n}^{2}}{p^{2}+2 \omega_{n} \zeta p+\omega_{n}^{2}} \mathscr{L}\left[v_{x}(t) \delta_{c}(t)\right]\right] \int_{(5)}
\end{array}\right\}
$$

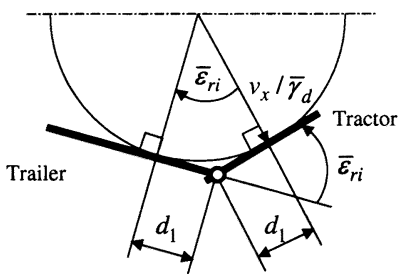

Fig. 2 Notation to design an ideal trajectory $\varepsilon_{r d}$.

Table 1 Notation of model.

\begin{tabular}{ll}
\hline \hline$v_{x}, v_{y}$ & velocities of the tractor \\
$\gamma_{1}, \gamma_{2}, \varepsilon_{r}$ & yaw rates and relative yaw angle \\
$\delta_{f}, \delta_{r}, \delta_{t}$ & steering angles \\
$m_{1}, m_{2} \quad$ mass of the tractor and trailer \\
$I_{z 1}, I_{z 2} \quad$ moment of inertia of tractor and trailer \\
$\ell_{f}, \ell_{r} \quad$ distances from the tractor C.G. to front \\
& and rear wheel axle \\
$\ell_{t}$ & length of trailer \\
$d_{1}, d_{2}$ & distance from the connector to C.G. \\
$\alpha_{f}, \alpha_{r}, \alpha_{t}$ & lateral slip angles at wheels \\
$c_{f}, c_{r}, c_{t}$ & cornering stiffness
\end{tabular}

指令舵角 $\delta_{c}(t)$ ならびに車速 $v_{x}(t)$ が一定（定常円 旋回）の場合，牽引車の理想横方向速度 $v_{y d}(t)$ は零 に漸近し, 理想ヨーレイト $\gamma_{d}(t)$ は一定值に収束する $\left(\lim _{t \rightarrow \infty} \gamma_{d}(t)=\bar{\gamma}_{d}\right)$. そして, 牽引車は半径 $v_{x} / \bar{\gamma}_{d}$ の円に 接して走行することになる.このことが，理想軌道を 式 (5) で与える利点の一つである. 牽引車が半径 $v_{x} / \bar{\gamma}_{d}$ の円に接して走行するとき，トレーラもこの円に接す ることが理想的であると考える（図 2 参照）。牽引車 とトレーラが半径 $v_{x} / \bar{\gamma}_{d}$ の円に接して走行していると き, 図 2 の相対ヨ一角 $\bar{\varepsilon}_{r i}$ は次式で与えられる.

$$
\bar{\varepsilon}_{r i}=\tan ^{-1} \frac{2 d_{1} v_{x} \bar{\gamma}_{d}}{v_{x}^{2}-\left(d_{1} \bar{\gamma}_{d}\right)^{2}} \approx \frac{2 d_{1} v_{x} \bar{\gamma}_{d}}{v_{x}^{2}-\left(d_{1} \bar{\gamma}_{d}\right)^{2}}
$$

以上のことを考慮に入れ，車線変更時には理想相対ヨ 一角がなるべく小さくなるように，理想相対ヨ一角を 次式の形で与えることを提案する.

$$
\left.\begin{array}{l}
\mathscr{L}\left[\varepsilon_{r d}(t)\right]=\frac{\omega_{n \varepsilon}^{2}}{p^{2}+2 \omega_{n \varepsilon} \zeta_{\varepsilon} p+\omega_{n \varepsilon}^{2}} \mathscr{L}\left[\varepsilon_{r i}(t)\right] \\
\varepsilon_{r i}(t)=\frac{2 d_{1} v_{x}(t) \gamma_{d}(t)}{v_{x}(t)^{2}-\left(d_{1} \gamma_{d}(t)\right)^{2}}
\end{array}\right\}
$$

以上述べた理想軌道の状態空間表現を示しておく.

$$
\left.\begin{array}{l}
\dot{\eta}_{d}(t)=A_{d} \eta_{d}(t)+v_{x}(t) \omega_{n}^{2} b_{d} \delta_{c}(t) \\
\gamma_{d}(t)=g_{\gamma}\left(v_{x}\right) c_{d}^{T} \eta_{d}(t), v_{y d}(t)=g_{v y} b_{d}^{T} \eta_{d}(t) \\
\eta_{d}(0)^{T}=\left[\gamma_{1}(0) / g_{\gamma}\left(v_{x}(0)\right), v_{y}(0) / g_{v y}\right]
\end{array}\right\}
$$

$\left.\dot{\eta}_{\varepsilon d}(t)=A_{\varepsilon d} \eta_{\varepsilon d}(t)+\omega_{n}^{2} b_{d} \varepsilon_{r i}(t), \varepsilon_{r d}(t)=c_{d}^{T} \eta_{\varepsilon d}(t)\right\}$ 
Table 2 Nominal values of parameters

\begin{tabular}{crlcrl}
\hline$m_{1}$ & 1180 & $\mathrm{~kg}$ & $I_{z 1}$ & 1570 & $\mathrm{kgm}^{2}$ \\
$\ell_{f}$ & 1.2 & $\mathrm{~m}$ & $\ell_{r}$ & 1.3 & $\mathrm{~m}$ \\
$d_{1}$ & 2 & $\mathrm{~m}$ & $d_{2}$ & 2 & $\mathrm{~m}$ \\
$c_{f}$ & 24400 & $\mathrm{~N} / \mathrm{rad}$ & $c_{r}$ & 34600 & $\mathrm{~N} / \mathrm{rad}$ \\
$m_{2}$ & 490 & $\mathrm{~kg}$ & $I_{z 2}$ & 390 & $\mathrm{kgm}$ \\
$\ell_{t}$ & 2.1 & $\mathrm{~m}$ & $c_{t}$ & 34600 & $\mathrm{~N} / \mathrm{rad}^{2}$ \\
\hline
\end{tabular}

$\left.\begin{array}{l}\left.A_{d}=\left[\begin{array}{cc}0 & 1 \\ -\omega_{n}^{2}-2 \omega_{n} \zeta\end{array}\right], A_{\varepsilon d}=\left[\begin{array}{cc}0 & 1 \\ -\omega_{\varepsilon n}^{2}-2 \omega_{\varepsilon n} \zeta_{\varepsilon}\end{array}\right]\right\} \\ b_{d}=[0,1]^{T}, c_{d}=[1,0]^{T}\end{array}\right\}$

3.2 パラメータ設定法 前項で示した理想軌道 の各設計パラメータの一設定法を説明する．理想軌道 の設計を簡単にするため, $\omega_{n}=\omega_{\varepsilon n}, \zeta=\zeta_{\varepsilon}$ として理 想軌道を設計した. なお，用いた牽引車とトレーラの 各パラメータのノミナル值を表 2 (7) に示しておく.

作成した理想モデルのパラメータ值を次式に示す.

$$
\left.\begin{array}{l}
\zeta=1, g_{\gamma}\left(v_{x}\right)=\frac{2.10 \times 10^{2}}{5.25 \times 10^{2}+1.82 v_{x}(t)^{2}} \\
\omega_{n}=10, g_{v y}=0.36
\end{array}\right\}
$$

図 3 の指令舵角を用いたときの理想軌道を図 4 に示す. 図 3 において Maneuver 1 は車線変更用の指令舵角で あり，Manuver2 は円旋回用の指令舵角である。車速 は $v_{x}(t)=120 \times 10 / 36 \mathrm{~m} / \mathrm{s}$ である. 図 4 (a)-(e)が車線 変更の場合の理想軌道であり, 図 4 (f)-(j) が円旋回の 場合の理想軌道である. 図 4 (e),(j) において太い実線 で牽引車の前輪の軌跡を示し, 細い実線でトレーラ輪 の軌跡を示している. なお, 図 4 (e) では両車輪軌跡 が重なっている. また, 図 4 (j) は旋回半径約 $400 \mathrm{~m}$ の 車輪軌跡の初期の軌跡を示したものでる.

ゲイン $g_{\gamma}\left(v_{x}\right)$ の值は, 表 2 で与えられるノミナル值 を用いた連結車両（以下ノミナル車両と呼ぶ）において 車速 $v_{x}(t)$ が一定の場合に, 前輪操舵角からヨーレイト までの伝達関数の $p=0$ の場合のゲインと $g_{\gamma}\left(v_{x}\right) v_{x}(t)$ が等しくなるように設定している．また，理想軌跡が 振動的にならないように メータ $g_{v y}, \omega_{n}$ は, つぎの(1)〜(5)を考慮して試行錯誤 的に值を決定した. 車線変更においては, (1)相対ヨー 角ならびに横方向加速度の絶対值をなるべく小さくす る. (2)車輪軌跡の初期の横方向への移動をなるべく早 くする. 円旋回においては, (3)牽引車の前輪軌跡と卜 レーラ輪軌跡がなるべく離れないようにする. (4)過渡 的な横加速度が定常円旋回において必要となる横加速 度より大きくならないようにする. (5)ヨーレイト, 相 対ヨー角の定常值への収束時間をなるべく短くする.

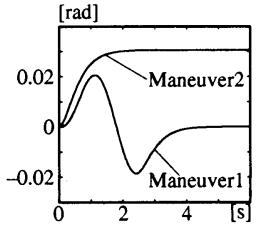

Fig. 3 Ordered steering angles $\delta_{c}$.

\section{4. ロバスト追従コントローラ}

連結車両のパラメータが変動した場合, 連結車両の 操舵特性が変化する. この変化が大きい場合には, 操 縦者はその変化に対応するためにかなりの苦労をする ことになる，不慣れな操䋛者の場合には，操舵特性の 変化に対応できず車両の挙動が不安定となることもあ るであろう。しかし，実際の連結車両の挙動を作成し た理想軌道に追従させることができれば，たとえ実際 の連結車両のパラメータが変動しても操縋者はその変 動を感じることなく操縦でき, 高い操縋安定性能を確 保できることになる.

以下では, 前項で示した 3 つの理想軌道 $v_{y d}(t)$, $\gamma_{d}(t), \varepsilon_{r d}(t)$ に実際の連結車両を追従させるコントロー ラを開発する.これら 3 つの信号に実際の連結車両が 追従したとき, 横方向加速度 $a(t)=\dot{v}_{y}(t)+v_{x}(t) \gamma_{1}(t)$ も理想横方向加速度 $a_{d}(t)$ に追従することが期待され る. このことは次節の数值シミュレーションにおいて 示す．まず最初にコントローラ開発に用いた追従誤差 方程式を示し，その後，提案するコントローラを説明 する.なお，以下において $I_{n}, 0_{n}$ は，それぞれ， $n \times n$ 次の単位行列, $n \times n$ の零行列である.

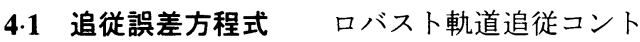
ローラを設計するために, 連結車両の新たな運動方 程式表現を導出しておく. なお，導出には $B_{p}^{T} b=\ell_{t} b$, $D_{p} b=[0,0,0]^{T}$ となることを用いている. 状態を

$$
x(t)=B_{p}^{T}\left[h_{x}^{-1} q(t)+b \varepsilon_{r}(t)\right]
$$

とすれば, 連結車両の運動方程式は, 式 (1) より, 次 式で与えられることがわかる. $h_{x}$ は追従性能を改善す るために導入した正の設計パラメータである.なお, $M$ は正定行列である.

$$
\begin{gathered}
\left.\begin{array}{rl}
\dot{x}(t) & =\left(v_{x}(t) M^{-1} D+h_{x} E\right) x(t)-h_{x} \ell_{t} b \varepsilon_{r}(t)+h_{x}^{-1} M^{-1} f(t) \\
f(t) & =C_{p}\left[u(t)-\frac{h_{x}}{v_{x}(t)} x(t)+\left(\frac{h_{x} \ell_{t}}{v_{x}(t)}-1\right) b \varepsilon_{r}(t)\right]
\end{array}\right\} \\
\left.\begin{array}{c}
M=B_{p}^{-1} M_{p}\left(B_{p}^{-1}\right)^{T}, D=B_{p}^{-1} D_{p}\left(B_{p}^{-1}\right)^{T} \\
E=\ell_{t} b b^{T}\left(B_{p}^{-1}\right)^{T}
\end{array}\right\}
\end{gathered}
$$




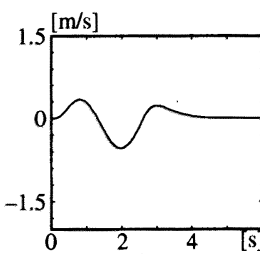

(a) $v_{y d}$
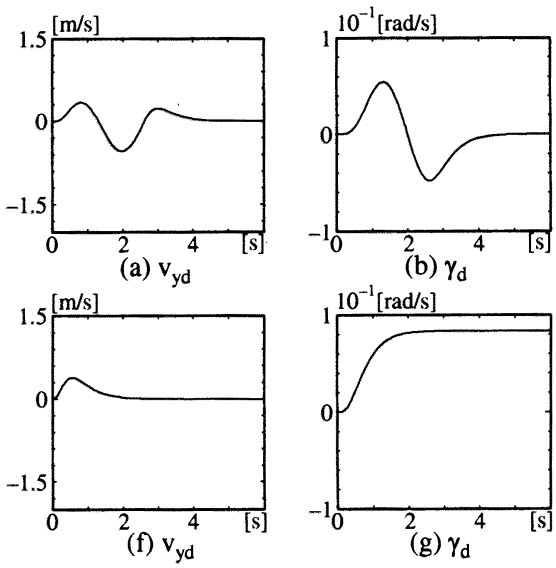

(b) $\gamma_{\mathrm{d}}$

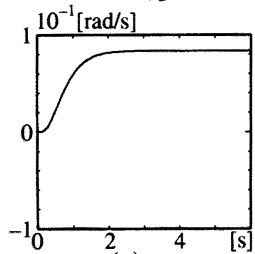

(g) $\gamma_{\mathrm{d}}$

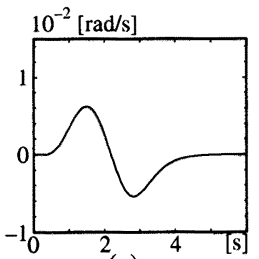

(c) $\varepsilon_{\mathrm{rd}}$

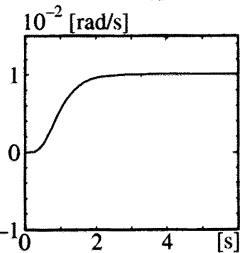

(h) $\varepsilon_{\mathrm{rd}}$

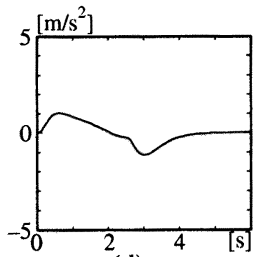

(d) $a_{d}$

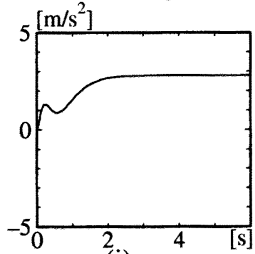

(i) $a_{d}$

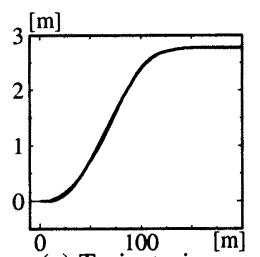

(e) Trajectories

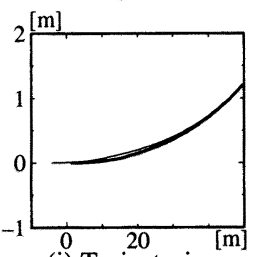

(j) Trajectories

Fig. 4 Ideal trajectories.

追従誤差を

$$
\left.\begin{array}{rl}
\tilde{\varepsilon}_{r}(t) & =\varepsilon_{r}(t)-\varepsilon_{r d}(t), \widetilde{x}(t)=x(t)-x_{d}(t) \\
x_{d}(t) & =B_{p}^{T}\left(h_{x}^{-1} q_{d}(t)+b \varepsilon_{r d}(t)\right) \\
q_{d}(t) & =\left[v_{y d}(t), \gamma_{d}(t), \dot{\varepsilon}_{r d}(t)\right]^{T}
\end{array}\right\}
$$

で定義すれば追従誤差方程式は次式で与えられる.

$$
\left.\begin{array}{rl}
\dot{\tilde{x}}(t)= & \left(v_{x}(t) M^{-1} D+h_{x} E\right) \widetilde{x}(t)-h_{x} \ell_{t} b \widetilde{\varepsilon}_{r}(t) \\
& +h_{x}^{-1} M^{-1} f(t)+h_{x}^{-1} M^{-1} d(t) \\
d(t)= & v_{x}(t) B_{p}^{-1} D_{p} q_{d}(t)-M B_{p}^{T} \dot{q}_{d}(t)
\end{array}\right\}
$$

ここで, $d(t)$ は設計パラメータ $h_{x}$ に無関係な有界信 号であり，指令舵角が一定の場合には，ある一定值に 収束する信号である.

少なくとも一定な指令舵角と車速に対して追従誤差 $\tilde{x}(t)$ が零に収束するコントローラを設計するために， 積分器を導入した拡張誤差状態

$$
\xi(t)^{T}=\left[h_{x}\left(\int_{0}^{t} \tilde{x}(\tau) d \tau\right)^{T}, \tilde{x}(t)^{T}\right]
$$

を導入する，このとき，拡張誤差方程式は

$$
\begin{gathered}
M_{\xi} \dot{\xi}(t)=h_{x} M_{\xi} \Gamma_{\xi} \xi(t)+B_{\xi}\left(v_{x}(t) D+h_{x} M E\right) B_{\xi}^{T} \xi(t) \\
-h_{x} \ell_{t} B_{\xi} M b \widetilde{\varepsilon}_{r}(t)+h_{x}^{-1} B_{\xi} f(t)+h_{x}^{-1} B_{\xi} d(t) \\
f(t)=C_{p}\left[u(t)-\frac{h_{x}}{v_{x}(t)} x(t)+\left(\frac{h_{x} \ell_{t}}{v_{x}(t)}-1\right) b \varepsilon_{r}(t)\right] \\
\dot{\tilde{\varepsilon}}_{r}(t)=-h_{x} \widetilde{\varepsilon}_{r}(t)+h_{x} b^{T}\left(B_{p}^{T}\right)^{-1} B_{\xi}^{T} \xi(t) \\
M_{\xi}=\left[\begin{array}{c}
M 0_{3} \\
0_{3} M
\end{array}\right], \Gamma_{\xi}=\left[\begin{array}{ll}
0_{3} & I_{3} \\
0_{3} & 0_{3}
\end{array}\right], B_{\xi}=\left[\begin{array}{l}
0_{3} \\
I_{3}
\end{array}\right]
\end{gathered}
$$

で与えられる. 誤差システム (18), (19) に対しコント ローラを開発するために次の仮定を設ける.

A3 $\underline{\rho}_{m} y^{T} y \leq y^{T} M y \leq \bar{\rho}_{m} y^{T} y, \underline{\rho}_{c} y^{T} y \leq y^{T} C_{p} y$ for any $y$ を満足する既知正定值 $\underline{\rho}_{m}, \bar{\rho}_{m}, \underline{\rho}_{c}$ が存在する.

A4 $\|D\| \leq \bar{\rho}_{D}$ を満足する既知正定值 $\bar{\rho}_{D}$ が存在する.
4.2 コントローラの開発拡張誤差方程式 (18) において行列 $M_{\xi}, C_{p}$ は未知行列であるが, どちら も正定行列である.この特徽を用い文献 (17)，(18)に 示されている考え方を利用し，終局有界性 (17) を保証 できる新しいロバストモデル追従コントローラを開発 する.

リッカチ方程式

$$
\left.\begin{array}{l}
\Gamma_{\xi}^{T} P+P \Gamma_{\xi}-P B_{\xi} B_{\xi}^{T} P=-h_{p} I_{6} \\
h_{p}=\bar{\rho}_{m} \underline{\rho}_{m}^{-1}+\bar{v}_{x} \bar{\rho}_{D}+\bar{\rho}_{m}\left(2\left\|B_{p}^{-1}\right\|^{2}+\|E\|\right)
\end{array}\right\}
$$

の実正定行列解

$$
P=\left[\begin{array}{cc}
\left(\sqrt{h_{p}} \sqrt{2 \sqrt{h_{p}}+h_{p}}\right) I_{3} & \left(\sqrt{h_{p}}\right) I_{3} \\
\left(\sqrt{h_{p}}\right) I_{3} & \left(\sqrt{2 \sqrt{h_{p}}+h_{p}}\right) I_{3}
\end{array}\right]
$$

を用いて正定值関数を次式で与える. なお， $\bar{v}_{x}$ は走行 している道路の平均的な速度を表している．例えば， 一般の高速道路では， $\bar{v}_{x}=100 \times 10 / 36 \mathrm{~m} / \mathrm{s}$ である.

$$
V(t)=\underline{\rho}_{m}^{-1} \xi(t)^{T} M_{\xi}^{\frac{1}{2}} P M_{\xi}^{\frac{1}{2}} \xi(t)+\bar{\rho}_{m} \widetilde{\varepsilon}_{r}(t)^{2}
$$

ここで， $M_{\xi}^{\frac{1}{2}}$ は $M_{\xi}^{\frac{1}{2}} M_{\xi}^{\frac{1}{2}}=M_{\xi}$ の関係を満足す る正定行列である ${ }^{(19)}$. 仮定 $A 3, A 4$ ならびに $\xi(t)^{T} M_{\xi}^{\frac{1}{2}} P M_{\xi}^{\frac{1}{2}} \xi(t)=\xi(t)^{T} M_{\xi} P \xi(t)=\xi(t)^{T} P M_{\xi} \xi(t)$, $M_{\xi} \Gamma_{\xi}=\Gamma_{\xi} M_{\xi}=M_{\xi}^{\frac{1}{2}} \Gamma_{\xi} M_{\xi}^{\frac{1}{2}}$ が成り立つことを用いて， $V(t)$ の時間微分を解析することにより，

$$
\left.\begin{array}{rl}
\dot{V}(t) \leq & -h_{x} \frac{1}{\lambda_{\max }[P]} V(t)+2 h_{x}^{-1} \underline{\rho}_{m}^{-1} \xi(t)^{T} P B_{\xi} f(t) \\
& +h_{x} h_{\xi}(t) \xi(t)^{T} P B_{\xi} B_{\xi}^{T} P \xi(t)+\|d(t)\|^{2} h_{x}^{-3} \\
h_{\xi}(t) & =\underline{\rho}_{m}^{-2}\left(1+h_{x}^{-2} \frac{v_{x}(t)^{2}}{\bar{v}_{x}} \bar{\rho}_{D}+\bar{\rho}_{m}\left(\underline{\rho}_{m}+\|E\|+2 \ell_{t}^{2}\right)\right)
\end{array}\right\}
$$




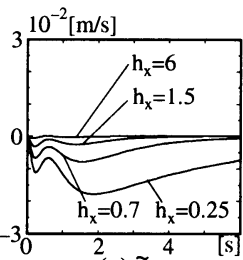

(a) $\tilde{\mathrm{v}}_{\mathrm{y}}$

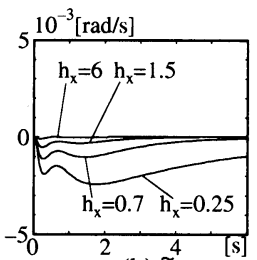

(b) $\tilde{\gamma}$

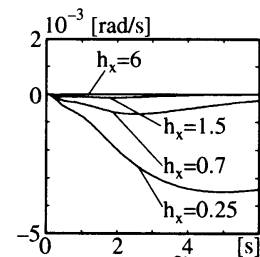

(c) $\frac{4}{\tilde{\varepsilon}_{\mathrm{r}}}$

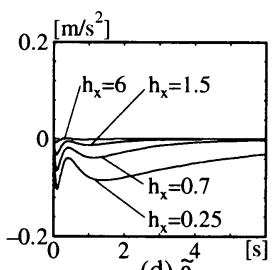

(d) $\tilde{a}$

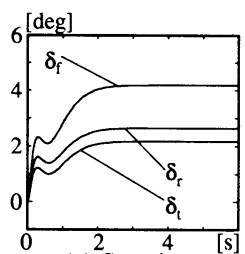

(e) Steering

Fig. 5 Tracking performance.

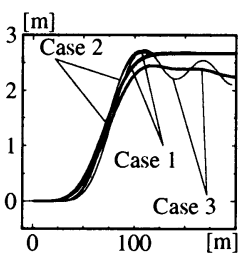

(a) Passive

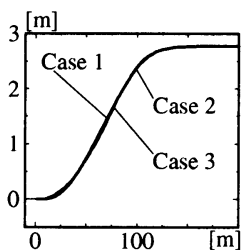

(e) New

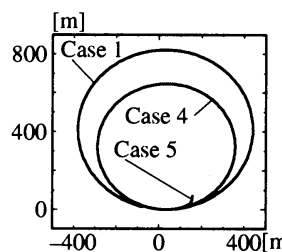

(b) Passive

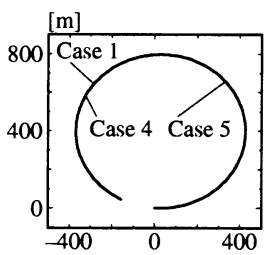

(f) New

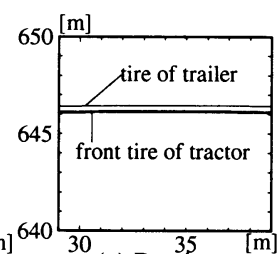

(c) Passive

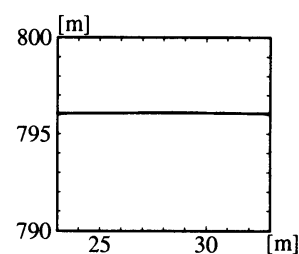

(g) New

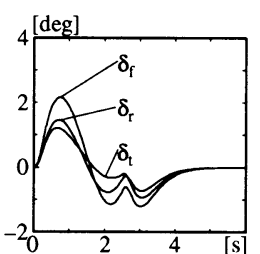

(d) Steering

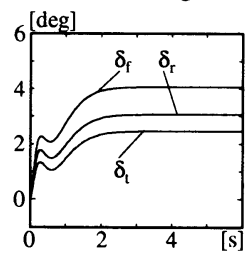

(h) Steering

Fig. 6 Robust performance.

の関係を得る (付録 $\mathrm{A}$ 参照) 。ここで, 入力舵角を

$$
\begin{aligned}
u(t)= & -\frac{h_{x}^{2} h_{\xi}(t) \underline{\rho}_{m}}{2 \underline{\rho} c} B_{\xi}^{T} P \xi(t)+\frac{h_{x}}{v_{x}(t)} x(t) \\
& -\left(\frac{h_{x} \ell_{t}}{v_{x}(t)}-1\right) b \varepsilon_{r}(t)
\end{aligned}
$$

とすれば，つぎの関係が満足されることがわかる.

$$
\dot{V}(t) \leq-h_{x} \lambda_{\max }[P]^{-1} V(t)+h_{x}^{-3} \bar{\rho}_{d}^{2}
$$

$\bar{\rho}_{d}$ は $\|d(t)\| \leq \bar{\rho}_{d}$ の関係を満足する設計パラメー 夕 $h_{x}$ に無関係に定まる正定值である. 上式より，入 力舵角 (25) を用いた追従制御系は終局有界 (17) とな り，V(0)=0を考慮すれば，次の関係が満足されるこ とがわかる ${ }^{(18)}$. なお, 次式において, $\widetilde{v}_{y}(t), \widetilde{\gamma}(t)$ は $\widetilde{v}_{y}(t)=v_{y}(t)-v_{y d}(t), \widetilde{\gamma}(t)=\gamma_{1}(t)-\gamma_{d}(t)$ で与えられる 誤差信号である.

$$
\left.\begin{array}{l}
\tilde{v}_{y}(t)^{2} \leq \frac{\lambda_{\max }[P] \bar{\rho}_{d}^{2}\left\|B_{p}^{-1}\right\|^{2}}{h_{x}^{2} \lambda_{\min }[P]} \\
\tilde{\gamma}(t)^{2} \leq \frac{\lambda_{\max }[P] \bar{\rho}_{d}^{2}\left\|B_{p}^{-1}\right\|^{2}}{h_{x}^{2} \lambda_{\min }[P]}, \widetilde{\varepsilon}_{r}(t)^{2} \leq \frac{\lambda_{\max }[P] \bar{\rho}_{d}^{2}}{h_{x}^{4} \bar{\rho}_{m}}
\end{array}\right\}
$$

また，若干の解析を行うことにより，指令舵角と車速 が一定の場合には，追従誤差が零に収束することも示 すことができる（付録 $\mathrm{B}$ 参照）。
上述したように, 入力舵角 (25) を用いれば車両パ ラメータに未知変動が存在したとしても連結車両の挙 動を理想モデルに追従させることができることがわか る. そして, 式 (27) の関係より, 設計パラメータ $h_{x}$ を大きくすることにより, 追従性能を簡単に改善でき ることがわかる，さらに，指令舵角と車速が一定の場 合には, 連結車両の挙動が理想モデルに一致すること も理論的に保証されることになる.

\section{5. 数値シミュレーション結果}

本稿で提案する操舵法の有効性を示すために行った 数値シミュレーション結果を示寸. 連結車両のノミナ ル値は表 2 で与えられ, 実際の連結車両の各パラメー タ・がノミナル值・と末知変動 $\Delta \bullet$ を用いて・ $=\mathbf{0}+\Delta \bullet$ の形で与えられるものとする. そして, $m_{2}, I_{z 2}, d_{2}$, $c_{f}, c_{r}, c_{f}$ の未知変動が

$$
\left.\begin{array}{l}
0 \leq \Delta m_{2} \leq 120 \mathrm{~kg}, \quad 0 \leq \Delta I_{z 2} \leq 100 \mathrm{kgm}^{2} \\
\left|\Delta d_{2}\right| \leq 0.2 \mathrm{~m}, \quad\left|\Delta c_{f}\right| \leq 5 \times 10^{3} \mathrm{~N} / \mathrm{rad} \\
\left|\Delta c_{r}\right| \leq 10^{4} \mathrm{~N} / \mathrm{rad}, \quad\left|\Delta c_{t}\right| \leq 10^{4} \mathrm{~N} / \mathrm{rad}
\end{array}\right\}
$$

を満足するものとする. $\Delta J_{z 2}, \Delta d_{2}$ の上限值は， $\Delta m_{2}$ が未知変動 (28) で示される範囲の荷物をトレーラの $1 \mathrm{~m} \leq \ell_{m} \leq 2 \mathrm{~m}$ の位置に置いた場合の最大変動值を示 
している. また, $c_{f}, c_{r}, c_{t}$ に関しては約 $20 \%$ の変 動を考えている. なお，上記以外の未知変動量は零で ある. 未知変動を考慮したとき, 仮定 A3，A4 の条件 を満足する正定值として次式を得る.

$$
\bar{\rho}_{m}=1040, \underline{\rho}_{m}=345, \underline{\rho}_{c}=19400, \bar{\rho}_{D}=670
$$

タイヤの非線形特性を考慮した場合においても提 案するコントローラが有効であることを示すために, 以下で示すシミュレーションでは，各車輪のすべり角 $\alpha(t)$ とコーナリングフォース $f(t)$ との関係を次式で与 えている ${ }^{(20)} . \mu$ は路面摩擦係数を表している. $\mu=1$ のときのすべり角とコーナリングフォースとの関倸に おける原点 $\left(\alpha_{i}(t)=0\right)$ での傾きが, それぞれ, $\bar{c}_{f}, \bar{c}_{r}$, $\bar{c}_{t}$ と等しくなるようにパラメータ $\bar{f}_{i j}$ の值を設定して いる.なお， $\mu$ が $0.5 \leq \mu \leq 1$ の間で変動したときの 次式の原点 $\left(\alpha_{i}(t)=0\right)$ での傾きのノミナル值 $\bar{c}_{f}, \bar{c}_{r}$, $\bar{c}_{t}$ からの変動量は未知変動 $(28)$ で与えられる範囲内 に存在する.

$$
\left.\begin{array}{c}
f_{i}(t)=\bar{f}_{1 i} \mu \sin \left[( \frac { 5 } { 4 } - \frac { \mu } { 4 } ) \overline { f } _ { 2 i } \operatorname { t a n } ^ { - 1 } \left[\bar{f}_{3 i}(2-\mu)\right.\right. \\
\times\left(1-\bar{f}_{4 i}\right) \alpha_{i}(t)+f_{4 i} \tan ^{-1}\left(\bar{f}_{3 i}(2-\mu)\right. \\
\left.\left.\left.\times \alpha_{i}(t)\right)\right]\right], \quad i=f, r, t \\
\bar{f}_{1 f}=4600, \bar{f}_{2 f}=1.1, \bar{f}_{3 f}=4.822, \bar{f}_{4 f}=-1.6 \\
\bar{f}_{1 r}=3600, \bar{f}_{2 r}=1.1, \bar{f}_{3 r}=8.687, \bar{f}_{4 r}=-1.6 \\
\bar{f}_{1 t}=3600, \bar{f}_{2 t}=1.1, \bar{f}_{3 t}=8.687, \bar{f}_{4 t}=-1.6
\end{array}\right\}
$$

図 5 (a)-(d) に, 車速 $120 \mathrm{~km} / \mathrm{h}$, 路面摩擦係数 $\mu=1$ で, 連結車両のすべての未知変動が零の場合において, 設計パラメータ $h_{x}$ を変化させた場合の提案する操舵 角 (25) を用いた連結車両（以下では新連結車両と呼 ぶ）と理想軌道との追従誤差応答を示す. 図 5 (e) に 設計パラメータが $h_{x}=6$ のときの新連結車両の操舵 角の応答を示す．なお，理想軌道への指令舵角は図 3 の Maneuver 2 を用いている.

図 5 (a)-(c)に示すように, 設計パラメータ $h_{x}$ を大 きくすることにより簡単に追従性能を改善でき，す心゙ ての追従誤差応答が零に収束していることがわかる. 図 5 (d)に示すように新連結車両の牽引車の横方向加 速度が理想方向加速度 $a_{d}(t)$ に追従することも確認で きる，また，図 5 (e)に示すように，操舵角は，高周 波振動をせず，滑らかになっていることがわかる.

つぎに, 新連結車両の強いロバスト性能を示すために 行ったシミュレーション結果を図 6 に示す. 図中の Case 1 Case 5 は, それぞれ, Case 1: $\mu=1$, 連結車両のす べての未知変動が零の場合, Case $2: \mu=0.7$, トレーラ の $\ell_{m}=2 \mathrm{~m}$ の位置に重さ $\Delta m_{2}=60 \mathrm{~kg}$ の荷物を置いた

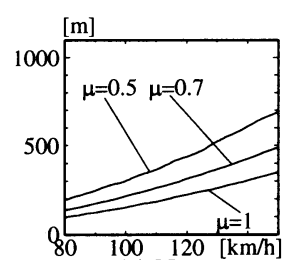

(a) New

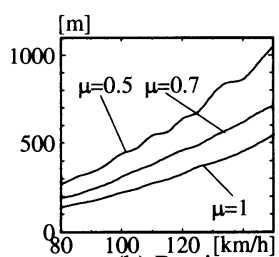

(b) Passive
Fig. 7 Limitation of circular driving.

場合, Case 3: $\mu=0.5$, トレーラの $\ell_{m}=2 \mathrm{~m}$ の位置に 重さ $\Delta m_{2}=120 \mathrm{~kg}$ の荷物を置いた場合, Case 4: $\mu=1$, トレーラの $\ell_{m}=1 \mathrm{~m}$ の位置に重さ $\Delta m_{2}=60 \mathrm{~kg}$ の荷物 を置いた場合, Case 5: $\mu=1$, トレーラの $\ell_{m}=1 \mathrm{~m}$ の位 置に重さ $\Delta m_{2}=120 \mathrm{~kg}$ の荷物を置いた場合である. 図 6 (a) (c) にパッシブ連結車両の牽引車前輪軌跡（太 い実線）とトレーラ輪軌跡（細い実線）を示し，図 6 (e) (g) に, 新連結車両の牽引車前輪軌跡 (太い実線) とトレーラ輪軌跡（細い実線）を示している.ただし， 図 6 (b),(e) (g) では, 両車輪軌跡が重なっている. な お, $h_{x}=6$ であり, 車速は $120 \mathrm{~km} / \mathrm{h}$ である. 図 6 (e) は指令舵角を図 3 の Maneuver 1 (約 $2.8 \mathrm{~m}$ の車線変更) で与えた場合の車輪軌跡であり, 図 6 (f) 汇指令舵角 を図 3 の Maneuver 2 (半径約 $400 \mathrm{~m}$ の円旋回）で与え た場合の車輪軌跡である. 図 6 (a),(b) は, Case 1 の場 合において理想軌道とパッシブ連結車両の挙動とがほ ぼ同じとなる牽引車前輪舵角を用いている. 図 6 (b) の Case 5 の車輪軌跡では, パッシブ連結車両が不安 定となったため, 途中でシミュレーションを中止した 軌跡を表示している. 図6 (c),(g) は, Case 4 の場合に 対する両車両軌跡（図 6 (b),(f)）の拡大図である. 図 6 (d) は図 6 (e) Case 3 の場合の新連結車両の操舵角 の応答であり, 図 6 (h) は図 6 (f) Case 5 の場合の新 連結車両の操舵角応答である. なお, Case 1〜Case 5 における理想軌道と連結車両との追従誤差は紙面の都 合上示していないが，図 5 の $h_{x}=6$ のときの追従誤差 応答とほぼ同程度の最大誤差の追従誤差応答となり, 時間とともにすべて零に収束する.

図6 (a),(b)に示すように, パッシブ連結車両では車 両パラメータの変化に対し車輪軌跡が変動し, Case 3, Case 5 の場合には車輪軌跡が不安定となっていること がわかる. しかし, 新連結車両では, 図 6 (e),(f)に示 すように, 車輪軌跡に変化がほとんど無いことがわか る.さらに，図6 (b),(f) を拡大表示した図 6 (c),(g) よ り, パッシブ連結車両においては, 率引車の前輪軌跡 とトレーラ輪軌跡が旋回半径方向に約 $0.3 \mathrm{~m}$ ずれてい るのに対し, 新連結車両においてはずれがほとんど生 


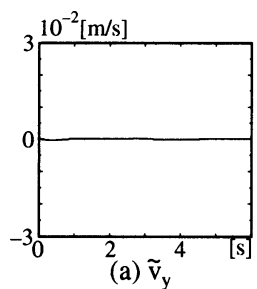

(a) $\tilde{v}_{y}$

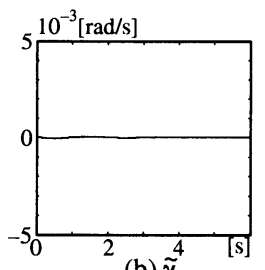

(b) $\tilde{\gamma}$

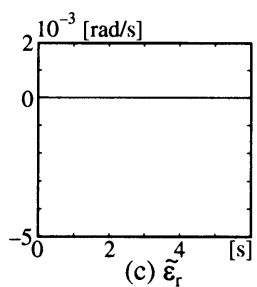

(c) $\widetilde{\varepsilon}_{\mathrm{r}}$

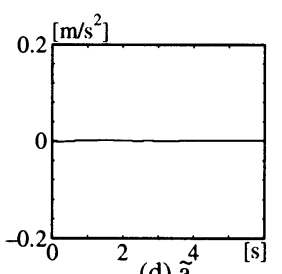

(d) $\tilde{a}^{4}$

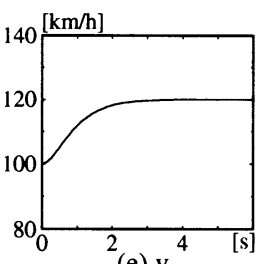

(e) $v_{x}$

Fig. 8 Robustness for the changes of velocity $v_{x}(t)$.

じていないことがわかる. パッシブ連結車両において は，トレーラ輪が操縦者が意図した旋回半径より大き な旋回半径で旋回することになる．もし障害物等が存 在する場合には, 操縦者が回避操舵を誤る原因となる ことも予想される. トレーラの長さ $\ell_{t}$ が長くなれば, より牽引車の前輪軌跡とトレーラ輪軌跡とのずれが広 くなり危険性がますことになる．また，図 6 (d),(h)に 示すように，操舵角は，高周波振動をせず，滑らかに なっていることがわかる.

図 7 は, パッシブ連結車両においては図 3 Maneuver 2 の最終値を増加させた舵角を前輪操舵角に印加し，新 連結車両では図 3 Maneuver 2 の最終值を増加させた 指令舵角を用いて旋回半径を短くしたときに，連結車 両が安定限界となる最小旋回半径を調べた結果を示 したものである。なお， $\mu$ 以外のシステムパラメータ には未知変動が存在しないものとして安定限界を調べ た. 横軸は車速であり縌軸は定常円旋回の半径を示し ている，例えば，図 7 (a)において，車速 $140 \mathrm{~km} / \mathrm{h}$ の とき, $\mu=1$ の場合には旋回半径が約 $300 \mathrm{~m}$ まで安定 に走行でき $300 \mathrm{~m}$ 末満の旋回半径では不安定となり, $\mu=0.7$ の場合には旋回半径が約 $450 \mathrm{~m}$ まで安定に走行 でき $450 \mathrm{~m}$ 末満の旋回半径では不安定となることを示 している. 図 7 に示すように, 新連結車両の方がパッ シブ連結車両に較べ，より短い旋回半径で安定に旋回 できることがわかる。

最後に, 車速変化ならびに前述の Case 5 の車両パラ メータ変化が存在する場合において, 新連結車両にお ける理想軌道と連結車両との追従誤差応答を図 8 に示 す. 図 8 (e)に車速変化を示している。なお，指令舵 角は図 3 Maneuver 2 を用い, 設計パラメータ $h_{x}=6$ を用いている．図 8 に示すように，車速が変化しても 新連結車両の理想軌道への追従性能はほとんど変化し ないことがわかる.

\section{6.お りりに}

連結車両に対し, 線形化運動方程式に基づいた新し いロバスト操縦安定化法を提案した．すなわち，まず，
理想軌道の一設計法を提案した。そして，操縦安定性 能を高めるためにロバス卜軌道追従法を提案した．本 手法では，線形化運動方程式で記述される連結車両に 対しては，一つの設計パラメータを用いて追従性能を 簡単に改善できることが理論的に保証される.タイヤ の非線形特性を考慮した数值シミュレーションを用い て，タイヤの非線形特性を考慮した非線形運動方程式 で記述される連結車両に対しても，設計パラメータを 用いて簡単に追従性能を改善できることを示した.さ らに, パラメータ変動に対し, パッシブ連結車両に比 へ，非常に強いロバスト操縦安定性能を持つことも示 した.

\section{文献}

(1) R.J.A. Kleuskens, and S.T.H. Jansen, The Influence of Central Axle Trailers and Steered Semi-Trailers on the Stability of Heavy Commercial Vehicles, Proceedings of International Symposium on Advanced Vehicle Control, (1992), pp. 327-333.

(2) 原田宏・原田正範, 連結車両の操舵安定限界と操縌安 定性評価，機論（C編），65-637, (1999), pp. 223-229.

（3）原田宏・原田正範・遠藤正幸，大型車両操縦安定性の 解析と評価 (操舵応答の感度解析と閉ループ系評価指 数)，機論 ( C 編), 67-657, (2001), pp. 334-340.

(4) S. Chikamori, Y. Shimizu, and K. Suzuki, Stability Analysis of Light Tractor and Semi-Trailer Combination when Trailer's Wheels are Steered, Proceedings of International Symposium on Advanced Vehicle Control, (1992), pp. 339-346.

(5) I. Kageyama, and R. Nagai, Stabilization of Passenger Car-Trailer System at High Speed, Proceedings of International Symposium on Advanced Vehicle Control, (1994), pp. 135-140.

(6) P. Fancher, H. Zhang, and C. Winkler, The Use of Braking for Controlling the Lateral Motion of Full Trailers, Proceedings of International Symposium on Advanced Vehicle Control, (1996), pp. 527-545.

（7）鈴木桂輔・近森順・清水裕・新庄弘之, トラクタ・セ ミトレーラ系のトレーラ輪を操舵した場合の安定性解 析, 機論 (C 編), 62-597, (1996), pp.91-98.

（8）竹村英孝，非線形操舵制御による連結車の操作性・安 定性向上，機論（C編），65-638, (1999), pp. 124-129. 
(9) C. Chen, and M. Tomizuka, Lateral Control of Commercial Heavy Vehicles, Vehicle System Dynamics, 33, (2000), pp. 391-420.

(10) M. Tai, and M. Tomizuka, Nonlinear Robust Loop Shaping Controller design for Automated lane Guidance of Heavy Vehicles, Proceedings of the American Control Conference, (2000), pp. 2028-2032.

(11) J.-Y. Wang, and M. Tomizuka, Gain-Scheduled $\mathrm{H}_{\infty}$ LoopShaping Controller for Automated Guidance of TractorSemitrailer Combination Vehicles, Proceedings of the American Control Conference, (2000), pp. 2033-2037.

(12) J.-Y. Wang, and M. Tomizuka, Reachability Analysis of Hybrid Lateral control Problem for Automated HeavyDuty Vehicles, Proceedings of the American Control Conference, (2001), pp. 1-6.

(13) M. Tai, and M. Tomizuka, Experimental Study of Lateral Control of Heavy Vehicles for Automated Highway Systems (AHS), Proceedings of the American Control Conference, (2002), pp. 851-856.

(14) L. Palkovics, and J. Bokor, Stabilization of a Car-Caravan Combination Using Active Unilateral Brake Control, Proceedings of International Symposium on Advanced Vehicle Control, (1994), pp. 141-146.

(15) P. Lugner, M. Plochl, and A. Riepl, Investigation of Passenger Car-Trailer Dynamics Controlled by Additional Braking of the Trailer, Proceedings of International Symposium on Advanced Vehicle Control, (1996), pp. 763778.

(16) D. de Bruin, and P.P.J. van den Bosch, Modeling and Control of a Double Articulated Vehicle with Four Steerble Axles, Proceedings of the American Control Conference, (1999), pp. 3250-3254.

(17) M. J. Corless and G. Leitmann, Continuous State Feedback Guaranteeing Uniform Ultimate Boundedness for Uncertain Dynamic Systems, IEEE Trans. Automatic Control, 26-5, (1981), pp. 1139-1144.

（18）大屋勝敬・西村行雄・米澤洋, 入出力部に非線形特性 をもつ系のモデル規範型制御, 計測自動制御学会論文 集, 26-3, (1990), pp. 36-43.

(19) 児玉慎三・須田信英, システム制御のためのマトリク 又理論, 計測自動制御学会, (1988).

(20) S. Mammar, and D. Koeing, Vehicle Handling Improvement by Active Steering, Vehicle System Dynamics, 38-3, (2002), pp. 211-242.

\section{付 録 A}

以下の関係が成り立つことを用いて変形することに より(24) が導出される.

$$
\left.\begin{array}{c}
2 v_{x}(t) \underline{\rho}_{m}^{-1} \xi(t)^{T} P B_{\xi} D B_{\xi}^{T} \xi(t) \\
\leq \frac{v_{x}(t)^{2} \bar{\rho}_{D}}{h_{x} \rho_{m}^{2} \bar{v}_{x}}\left\|B_{\xi}^{T} P \xi(t)\right\|^{2}+h_{x} \bar{v}_{x} \bar{\rho}_{D}\|\xi(t)\|^{2} \\
2 h_{x} \underline{\rho}_{m}^{-1} \xi(t)^{T} P B_{\xi} M E B_{\xi}^{T} \xi(t) \\
\leq \frac{h_{x} \bar{\rho}_{m}\|E\|}{\underline{\rho}_{m}^{2}}\left\|B_{\xi}^{T} P \xi(t)\right\|^{2}+h_{x} \bar{\rho}_{m}\|E\|\|\xi(t)\|^{2} \\
-2 h_{x} \ell_{t} \underline{\rho}_{m}^{-1} \xi(t)^{T} P B_{\xi} M b \widetilde{\varepsilon}_{r}(t) \\
\leq \frac{2 h_{x} \ell_{t}^{2} \bar{\rho}_{m}}{\rho_{m}^{2}}\left\|B_{\xi}^{T} P \xi(t)\right\|^{2}+\frac{h_{x} \bar{\rho}_{m}}{2} \widetilde{\varepsilon}_{r}(t)^{2} \\
2 h_{x} \bar{\rho}_{m} \widetilde{\varepsilon}_{r}(t) b^{T}\left(B_{p}^{T}\right)^{-1} B_{\xi}^{T} \xi(t) \\
\leq \frac{h_{x} \bar{\rho}_{m}}{2} \widetilde{\varepsilon}_{r}(t)^{2}+2 h_{x} \bar{\rho}_{m}\left\|B_{p}^{-1}\right\|^{2}\|\xi(t)\|^{2} \\
2 h_{x}^{-1} \underline{\rho}_{m}^{-1} \xi(t)^{T} P B_{\xi} d(t) \\
\leq h_{x} \underline{\rho}_{m}^{-2}\left\|B_{\xi}^{T} P \xi(t)\right\|^{2}+h_{x}^{-3}\|d(t)\|^{2}
\end{array}\right\}
$$

\section{付 録 B}

入力舵角 (25) を用いたとき追従誤差システムは

$$
\begin{aligned}
\dot{\xi}(t)= & h_{x} \Gamma_{\xi} \xi(t)+B_{\xi}\left(v_{x}(t) M^{-1} D+h_{x} E\right) B_{\xi}^{T} \xi(t) \\
& -h_{x} \ell_{t} B_{\xi} b \widetilde{\varepsilon}_{r}(t)-\frac{h_{x} h_{\xi}(t) \underline{\rho}_{m}}{2 \underline{\rho}_{c}} B_{\xi} M^{-1} C_{p} B_{\xi}^{T} P \xi(t) \\
& +h_{x}^{-1} B_{\xi} M^{-1} d(t) \\
& \dot{\tilde{\varepsilon}}_{r}(t)=-h_{x} \widetilde{\varepsilon}_{r}(t)+h_{x} b^{T}\left(B_{p}^{T}\right)^{-1} B_{\xi}^{T} \xi(t)
\end{aligned}
$$

と表現される.ここで, 新しく $z_{\xi}(t)=\dot{\xi}(t), z_{\varepsilon}(t)=$ $\dot{\widetilde{\varepsilon}}_{r}(t)$ とおけば, 車速 $v_{x}(t)$ が一定の場合, (36), (37) より

$$
\left.\begin{array}{rl}
\dot{z}_{\xi}(t)= & h_{x} \Gamma_{\xi} z_{\xi}(t)-\frac{h_{x} h_{\xi}(t) \underline{\rho}_{m}}{2 \underline{\rho}_{c}} B_{\xi} M^{-1} C_{p} B_{\xi}^{T} P z_{\xi}(t) \\
& +B_{\xi}\left(v_{x}(t) M^{-1} D+h_{x} E\right) B_{\xi}^{T} z_{\xi}(t) \\
& -h_{x} \ell_{t} B_{\xi} b z_{\varepsilon}(t)+h_{x}^{-1} B_{\xi} M^{-1} \dot{d}(t) \\
\dot{z}_{\varepsilon}(t)= & -h_{x} z_{\varepsilon}(t)+h_{x} b^{T}\left(B_{p}^{T}\right)^{-1} B_{\xi}^{T} z_{\xi}(t)
\end{array}\right\}
$$

の関係を得る. 指令舵角が一定の場合, $\dot{d}(t)$ は零に収 束する信号になる. $\dot{d}(t)=0$ のときのシステム (38) は, $d(t)=0$ のときのシステム (36), (37) と同じシステム となるので, 漸近安定である.このことより, 指令舵 角と車速が一定の場合, $z_{\xi}(t)$ は零に収束することに なる. $z_{\xi}(t)=\dot{\xi}(t)$ の関係より, 追従誤差 $\widetilde{v}_{y}(t), \tilde{\gamma}(t)$, $\widetilde{\varepsilon}_{r}(t)$ が零に収束することがわかる. 